\title{
The Influence of Age and Gender on Normalized Foot Arch Height in Childhood and Adolescence: Cross-sectional Study
}

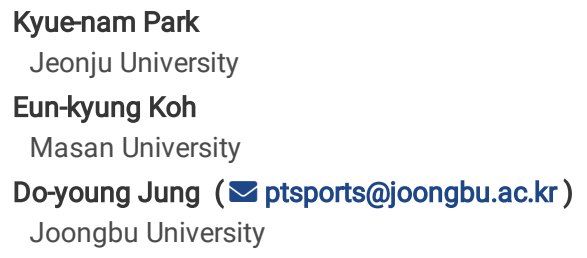

\section{Research Article}

Keywords: Children, Foot type, Normal foot development

Posted Date: March 22nd, 2021

DOI: https://doi.org/10.21203/rs.3.rs-330423/v1

License: () (i) This work is licensed under a Creative Commons Attribution 4.0 International License. Read Full License 


\section{Abstract}

Normalized arch height $(\mathrm{NAH})$, which can be calculated as the instep height $(\mathrm{IH})$ divided by total foot length (TFL), has been used when comparing the foot arch height, instead of navicular height $(\mathrm{NH})$ because of the difficulty to palpate navicular tuberosity when measuring $\mathrm{NH}$. The aim of current study was to investigate to investigate association between foot length and arch height, change in NAH over age, and distribution of foot type according to age in children and adolescent from 8 to 19 years. Foot scanning data of 1,451 children and adolescents were obtained. Four NAH indices were calculated as follows, 1) $\mathrm{NH} / \mathrm{TFL}$, 2) NH/instep length (IL), 3) IH/TFL and 4) IH/IL. There were significant positive relationships between foot length and arch height. Natural growth was observed in NH/TFL and NH/IL until 16 years old and IH/TFL and IH/IL between 11-13 and 14-16 years age groups. The proportions of pes planus also decreased, whereas the proportion of rectus foot type increased over age. Clinicians should be caution when diagnosing and designing non-surgical program for children with pes planus until 16 years old.

\section{Introduction}

Pes planus, characterized by lower arch height is the main reason for children to visit orthopaedist and podiatrist in order to observe and follow-up of foot arch height, even though of flatfoot in young people usually painless ${ }^{1-4}$. Because a recent review suggested the possibility of natural recovery of flatfoot with remaining stable after the age of 10 years and a decreasing trend of flatfoot over increasing age ${ }^{5}$, several researches suggested discouragement of any intervention in case of asymptomatic pes planus ${ }^{5-8}$. It is ambiguous and uncertain that clinicians should consider whether low MLA in children is one of the foot disorders or not.

There are several factors influencing arch height in childhood and adolescence such as age, gender, obesity, footwear habit and physical activity9-11. There are controversial as to growth of arch height over age. Based on data in Chinese school children, arch height showed greatest increases in children who ages were 7-12 years in both gender, while another longitudinal investigation study reported that the arch height of foot remained stable in children from 7 to 9 years old ${ }^{12,13}$. When it comes to gender, it is controversy that absolute arch height did not show statistical differences between gender ages $7-12$ years ${ }^{12}$, while some studies showed trends with higher arch height ratios in males than females ${ }^{8}$. Correlations between an increased body mass index (BMI), foot pain and flat feet have been found in children and youngsters ${ }^{14}$. Foot arch height is lower and foot length is greater in children who are obese than healthy controls ${ }^{15}$. In addition, type of footwear worn during childhood may influence the development of arch height of foot ${ }^{13}$. Previous study found that children who often wore closed-toe shoes at age 7 years had a flatter foot arch than those who used sandals and slippers, indicating that clinicians may discourage younger children from wearing slippers ${ }^{13}$.

In order to measure the height of foot arch, navicular height $(\mathrm{NH})$ has been used in previous literatures ${ }^{16-18}$. However, a previous study demonstrated that five raters with 3-7 years of clinical experience showed low to moderate interrater reliability of measurements of $\mathrm{NH}$ and high measurement error in the rage of $12 \%$ to $28 \%{ }^{18}$. The reason might be the difficulty to palpate navicular tuberosity when measuring $\mathrm{NH}$ and anatomical variations among each individual ${ }^{18,19}$. Then, instead of measurement of $\mathrm{NH}$, instep height $(\mathrm{IH})$, that is foot dorsal height at half of total foot length, was measured in the previous studies ${ }^{19}$. Another researchers suggested normalized arch height (NAH) which can be calculated as the IH, divided by total foot length ${ }^{19}$. A previous study reported that NAH was the reliable and valid method when comparing clinical and radiographic measurements of foot arch height ${ }^{19}$. Some previous studies reported differences in $\mathrm{NAH}$ according to age, gender, and $\mathrm{BMI}$ in children ${ }^{12,20}$.

The purposes of this study were 1) to investigate the relationship among BMI, arch height and NAH, 2) to compare foot length, arch height and NAH according to age and gender, and 3) to investigate the prevalence of foot type (pes planus and rectus) according to age in children and adolescent who were from eight to nineteen years old. This investigation would be helpful for clinicians and footwear manufacturers who manage the child and adolescents to give the meaningful information as to measurement and anthropometric variations of foot arch height and distribution of foot types.

\section{Methods}

\subsection{PARTICIPANTS AND DATA}

The data of this study were foot measurements of children and adolescents between the ages of 8 and 19 from fifth Size Korea survey of the Korea Technology Standard Institute (https://sizekorea.kr/page/report/3). In this survey, the foot measurements using the foot scanning were taken from March 2003 to November 2004 in 6 provinces of xxxxx. Among the data of 5,184 subjects, a total of 1,451 (male $=717$ and female $=734)$ subjects were used, excluding 3,733 subjects with other ages or missing data. This research has been approved by the research ethics committee of the xxxxxx xxxxxxxx.

\subsection{FOOT SCAN MEASUREMENTS}

In Size Korea survey, foot scan data were obtained in the following way: The INFOOT 3D Digitalizer model IF-21Series (I-Ware Laboratory Co., Ltd, Osaka, Japan) was used to scan the participant's feet. All methods of data collection met with international protocols for 3D scanning and human body measurements (ISO 15535). The 13 non-reflective green velvet markers were placed on the specific anatomical landmarks of foot. The subjects were then asked to step with the right foot in a resting stance position on to the glass footplate inside the laser scanner while the left foot was placed next to the scanner on a step of the same height. In order to gather anthropometric data of the feet, right lower limb was scanned using 3D imaging software with a scan pitch of $1.0 \mathrm{~mm}$ according to the procedure of the optical laser scanning 8,21 .

\subsection{DATA PROCESSING}


The four-measurement data are defined as follows. 1) total foot length (TFL): the distance between the pternion (most posterior point of the heel of the foot) and the longest toe measured along the foot axis, and the foot axis is defined as the segment of the foot sagittal from the posterior midpoint of the heel to the second toe. 2) instep length (IL): the distance from the posterior surface of the heel to the articular axis of the first metatarsophalangeal joint, 3) instep height $(\mathrm{IH})$ : the distance between the highest point on the instep and the support surface at 50\% of the total length of the foot, 4) navicular height ( $\mathrm{NH}$ ) (Figure 1$)$ : The distance between navicular tuberosity and the support surface. In this study, four NAH indices are obtained by calculating as follows from four feet measurement variables. 1) NH/TFL, 2) NH/IL, 3) IH/TFL, 4) IH/IL. BMI was calculated using the standard Quetelet index (body weight divided by height squared; $\mathrm{kg} / \mathrm{m}^{2}$ ). Foot types were determined using two types of $\mathrm{NAH}$ indices, which were calculated by $\mathrm{IH} / \mathrm{IL}$ and $\mathrm{NH} / \mathrm{IL}$. A pes planus was assigned if IH /IL .345 or less; a rectus foot structure if greater than $.345^{22}$. A previous study classified as pes planus when $\mathrm{NH} / \mathrm{IL}$ were under or same .194 and rectus when $\mathrm{NH} / \mathrm{IL}$ were over $.194^{23}$.

\subsection{DATA ANALYSES}

Kolmogorov-Smirnov test was performed as a normality test method to determine the nonparametric/parametric statistics for all foot measurement variables. As a result, it was found to be less than the significance level of .05 , indicating a non-normal distribution. Therefore, all data analysis was used as a nonparametric statistical method as follows. Spearman's Rank Order Correlation is used to find out the correlations between foot height or length and normalized arch height. Strength of correlation was defined as follows; weak range .20 .39, moderate range .40 .59, strong range .60 .79 and very strong $.80 \sim 1$. The Kruskal-Wallis test and Mann-Whitney $U$ test were used to find the mean difference of dependent variables according to ages and gender, respectively. The cross-tabulations with chi-square-test (X2-test) was performed to compare the distribution of arch types by age. Statistical analysis was performed with SPSS software (version 21.0; IBM Corp., Armonk, NY, USA), and the statistical significance level a is set to 05.

\section{Results}

\subsection{Correlation among variables}

BMI showed significantly positive correlation moderately with $\mathrm{IH}$ and weakly with $\mathrm{NH}$ and $\mathrm{NAH}$. In foot length, there were significantly positive correlation strongly between TFL and IH and between IL and IH. There was significantly positive correlation weak level between TFL and NH/TFL and between TFL and $\mathrm{NH} / \mathrm{IL}$ and significantly negative weak correlation between IL and IH/TFL and between IL and IH/IL. In arch height, IH showed significantly positive correlation strong with $\mathrm{NH}, \mathrm{IH} / \mathrm{FL}$ and $\mathrm{IH} / \mathrm{IL}$, moderate with $\mathrm{NH} / \mathrm{IL}$, weak level with $\mathrm{NH} / \mathrm{TFL}$. $\mathrm{NH}$ showed significantly positive correlation very strong with $\mathrm{NH} / \mathrm{TFL}$ and $\mathrm{NH} / \mathrm{IL}$, moderate with IH/TFL and IH/IL (Table 1).

\subsection{Effect of age on foot length, foot arch height and NAH}

Values of TFL, IL, IH, NH, NH/TFL and NH/IL were significantly getting higher by increasing age among 8-10 years, 11-13 years, and 14-16 years age groups ( $P$ $<.05)$, while did not significantly change by increasing age between $14-16$ years and 17-19 years age groups $(P>.05)$. IH/TFL and IH/IL were significantly higher by increasing age only between $11-13$ and $14-16$ years age groups $(P<.05)$ (Table 2) (Figure 2).

\subsection{Effect of gender on foot length, foot arch height and NAH}

In all age groups, foot length and arch height (TFL, IL, NH and IH) of males were significantly higher than those of female $(P<.05)$, whereas there were no differences between male and female in NAH (NH/TFL, NH/IL, IH/TFL and IH/IL) $(P>.05)$ except of IH/TFL in 11-13 years old $(P<.05)($ Table 2). In 11-13 years age group, IH/TFL of male was significantly higher than that of female $(P<.05)$.

\subsection{Distribution of foot type according to age}

Based on the classification criteria of IH/IL, statistically significant cross-tabulation were observed in several age groups by the foot type (Pearson chi square $=23.05, P=.001$ and $P$ value of linear-by-linear association $=.006)$. As age increased, the proportion of pes planus also decreased until $14-16$ age, whereas the proportion of rectus increased until 14-16 age (Table 3) (Figure 3).

Based on the classification criteria of $\mathrm{NH} / \mathrm{IL}$, statistically significant cross-tabulation were observed in several age groups by the foot type (Pearson chi square =24.53, $P<.001$ and $P$ value of linear-by-linear association $<.001)$. As age increased, the proportion of pes planus also decreased until 17-19 age, whereas the proportion of rectus increased until 17-19 age (Table 3) (Figure 3).

\section{Discussion}

Regarding the relationship between $\mathrm{BMI}$ and arch height $(\mathrm{IH}, \mathrm{NH}$ or $\mathrm{NAH})$, this study showed that higher BMI presented a trend toward-higher arched feet $(\rho=$ .13 .49). However, several previous studies have demonstrated that overweight and obesity negatively affect the arch height in children ${ }^{24-26}$. The inconsistent results with previous studies can be explained by the difference in study design and sample size. Previous studies examined the relationship between BMI and arch height in narrow range of age group, while our study selected wide range of age including the children and adolescence from 8 to 19 years old. Also, out of a total of 1,452 children and adolescence, $82 \%$ had normal body weight and $18 \%$ were only overweight and obese, based on BMI-for-age growth charts designed Cole et al. ${ }^{27}$. Because both $\mathrm{BMI}$ and arch height are growing over age in the parts of natural growing process, it is inevitable to show positive relationship between BMI and arch height in current study.

Regarding to results of non-NAH, there were significant positive relationships existed between foot length (TFL and IL) and arch height (IH and NH) in this study $(\rho=.39 \sim .71)$. In addition, IH had higher correlations with age, height, weight, BMI, TFL and IL than NH, indicating that IH may be clinically and 
manufactural more reflective for growth of the foot arch than $\mathrm{NH}$. As introduction section was mentioned, the measurement of IH is more reliable than $\mathrm{NH}$, because NH measurement has difficulty to palpate the navicular tuberosity. Therefore, based on current findings, a linear formula between IH and foot length may be used for scaling the arch of the footwear or insole according to the length of that for children. When it comes to results of NAH, previous study demonstrated moderate inversely relationships between foot length and NAH $(\rho=-.47 \sim-.53)$ in adults ${ }^{28}$. This result indicated that arch height gradient decreases as the foot length increases. However, in our study, correlations between foot length and NAH $(\rho=-.08 \sim-.07)$ were very weak. Compared with previous study, the reason for the lower correlation in our study is that, unlike adults, children increase arch height as foot length increase as they grow. Taken together of findings in both non-NAH and NAH, when making a decision of the dimensions of arch height of ergonomic shoe or insole, IH and $\mathrm{NAH}$ should be considered separately in case of the children and adult, respectively.

In Japanese children, TFL and NH continues its growth within 10-16 years of age ${ }^{8}$. In Chinese and Spanish children research, the greatest growth rates of TFL, $\mathrm{IL}, \mathrm{IH}$ and $\mathrm{NH}$ were in 7-11 years age ${ }^{12}$. Korean children in current study showed the largest growth rate peak of TFL, IL, IH, NH, NH/TFL and NH/IL (10.2\%, $9.6 \%, 10.8 \%, 12.8 \%, 3.3$ and $3.4 \%$ ) in 8-10 age group, followed by $11-13$ years old, indicating that foot morphology of Korea children would be growing up at age range of 8-13 years old. Additionally, we found significant differences between consecutive age groups in the range of 8-16 years old and then reached a plateau in 17-19 years old (Figure 1). We recommend that clinicians should be caution when diagnosing and designing non-surgical program for asymptomatic children with pes planus, because current data showed natural growth of foot arch until 16 years old.

When comparing the NAH in current subjects between 8-10 and 11-13 years old, contradicting results were observed depending on the kinds of normalization method. Growth of IH/FL and IH/IL showed no significant differences, while NH/FL and NH/IL showed significantly growth in 11-13 years rather than 8-10 years age group. In addition, the growth rates of $\mathrm{IH} / \mathrm{FL}$ and $\mathrm{IH} / \mathrm{IL}(0.8 \%$ and $1.2 \%)$ were lower than those of $\mathrm{NH} / \mathrm{FL}$ and $\mathrm{NH} / \mathrm{IL}$ (3.3\% and 3.4\%) between 8-10 and 11-13 years old. The plausible reason of these differences might be due to differences of numerator of IH/FL and IH/IL. The growth rate of IH (10.7\%) were lower than growth rate of $\mathrm{NH}(12.8 \%)$, leading to lower growth rate of $\mathrm{IH} / \mathrm{FL}$ and $\mathrm{IH} / \mathrm{IL}$ than $\mathrm{NH} / \mathrm{FL}$ and $\mathrm{NH} / \mathrm{IL}$, and insignificant grow-up of IH/FL and $\mathrm{IH} / \mathrm{IL}$.

Current findings also showed differences of foot length and height (FL, LL, NH and IH) between gender, larger in boys than in girls in all age groups, ranges from 6 to 19 years old. Previous studies also reported that absolute values of arch height and foot length in boys were higher than girls of the same age in Spanish children who were 6-12 years old ${ }^{20}$. Age at 8 and 10 years old showed the gap of foot growth between boys and girls, respectively ${ }^{12}$. When the arch heights were normalized to foot lengths, previous result showed no significant between-gender differences in either IH/FL and NH/FL, which may be explained by the foot length differences combined with the differences in arch height in both gender ${ }^{6,29}$. In same line with previous findings, between-gender differences were no longer significant in $\mathrm{NAH}(\mathrm{NH} / \mathrm{FL}, \mathrm{NH} / \mathrm{IL}, \mathrm{IH} / \mathrm{FL}$ and $\mathrm{IH} / \mathrm{IL})$.

In this study, $\mathrm{IH} / \mathrm{IL}$ and $\mathrm{NH} / \mathrm{IL}$ were used to determine the distribution of foot type among four $\mathrm{NAH}$ indexes ${ }^{22}$. Based on $\mathrm{IH} / \mathrm{IL}$ index, there were predominantly larger distributions of pes planus than rectus type in all age group. Similarly, our study' results, Drefus et al. ${ }^{30}$ reported that average IH/IL was . 32 and $90 \%$ of the children's feet was classified as pes planus in age range from 6 to 12 years. Although range of age was different from a previous study, average IH/IL was .31 and occupied $87.5 \%$ of pes planus in our study. To classify the foot type in a previous study, the standard value of IH/IL were obtained in adult population. Then, it is not suitable for children or adolescence to apply the criteria IH/IL for classifying the foot type. A previous study suggested the optimal cutoff point $(\mathrm{NH} / \mathrm{IL}<.19)$ for the diagnosis of pes planus using $\mathrm{NH} / \mathrm{IL}$ in children aged $6 \sim 12$ years. Based on $\mathrm{NH} / \mathrm{IL}$ index, distribution of pes planus decreased from $41.8 \%$ in 8-10 years age group to $25.0 \%$ in 17-19 years age group in current study. Although current study used IH/IL and NH/IL as sub-classification criteria for pes planus, we cannot generalize the results of distribution of foot type in children and adolescent, because IH/IL criteria is for adult population and NH/IL criteria can be just applied within age ranges $6 \sim 12$ years. Therefore, further study would be needed to determine the optimal cutoff point of IH/IL and NH/IL to diagnosis as pes planus in each separate age for children and adolescence populations.

There are some limitations of this study. First, current cross-sectional and correlational study could not explain the longitudinal development of foot arch in children and adolescence. Further study would be needed to investigate the relationship between age and longitudinal development of foot arch. Second limitation is convenience sampling method in pre-recorded open-source data that used in the current study. The sample in current study consisted of not many children with overweight and obese when classifying the different groups of BMI (overweight, obese and underweight), so we cannot clarify the cause and effect relationship between BMI and growth of foot arch. Third, we did not consider the other factors such as shoe type and level of the physical activity affecting the height of foot arch. These issues would be needed to investigate in future study.

\section{Conclusions}

The findings of current study showed that higher IH were significantly more correlated with higher age, BMI, TFL and IL, rather than NH. These findings indicate that $\mathrm{IH}$ may be clinically and manufactural more reflective for growth of the foot arch than $\mathrm{NH}$. In addition, current findings showed the natural growth of IH/TFL and IH/IL between 11-13 and 14-16 years age groups. Based on the classification criteria of NH/IL, the proportion of pes planus also decreased over age, whereas the proportion of rectus increased over age. We suggest that clinicians should be caution when diagnosing and designing non-surgical program for asymptomatic children and adolescents with pes planus, because current data showed natural growth of foot arch.

\section{References}

1 Halabchi, F., Mazaheri, R., Mirshahi, M. \& Abbasian, L. Pediatric flexible flatfoot; clinical aspects and algorithmic approach. Iran J Pediatr23, 247-260 (2013). 
2 Riccio, I., Gimigliano, F., Gimigliano, R., Porpora, G. \& Iolascon, G. Rehabilitative treatment in flexible flatfoot: a perspective cohort study. Chir Organi Mov93, 101-107 https://doi.org/10.1007/s12306-009-0037-z (2009).

3 Carr, J. B., 2nd, Yang, S. \& Lather, L. A. Pediatric Pes Planus: A State-of-the-Art Review. Pediatrics137, e20151230 https://doi.org/10.1542/peds.2015$1230(2016)$.

4 Bauer, K., Mosca, V. S. \& Zionts, L. E. What's New in Pediatric Flatfoot? J Pediatr Orthop36, 865-869 https://doi.org/10.1097/bpo.0000000000000582 (2016).

5 Dare, D. M. \& Dodwell, E. R. Pediatric flatfoot: cause, epidemiology, assessment, and treatment. Curr Opin Pediatr26, 93-100 https://doi.org/10.1097/mop.0000000000000039 (2014).

6 Stavlas, P., Grivas, T. B., Michas, C., Vasiliadis, E. \& Polyzois, V. The evolution of foot morphology in children between 6 and 17 years of age: a crosssectional study based on footprints in a Mediterranean population. J Foot Ankle Surg44, 424-428 https://doi.org/10.1053/j.jfas.2005.07.023 (2005).

7 Chang, J. H. et al. Prevalence of flexible flatfoot in Taiwanese school-aged children in relation to obesity, gender, and age. Eur J Pediatr169, 447-452 https://doi.org/10.1007/s00431-009-1050-9 (2010).

8 Waseda, A., Suda, Y., Inokuchi, S., Nishiwaki, Y. \& Toyama, Y. Standard growth of the foot arch in childhood and adolescence-derived from the measurement results of 10,155 children. Foot Ankle Surg20, 208-214 https://doi.org/10.1016/j.fas.2014.04.007 (2014).

9 Song, J. et al. Comprehensive biomechanical characterization of feet in USMA cadets: Comparison across race, gender, arch flexibility, and foot types. Gait Posture60, 175-180 https://doi.org/10.1016/j.gaitpost.2017.12.001 (2018).

10 Zhao, X., Gu, Y., Yu, J., Ma, Y. \& Zhou, Z. The Influence of Gender, Age, and Body Mass Index on Arch Height and Arch Stiffness. J Foot Ankle Surg59, 298-302 https://doi.org/10.1053/j.jfas.2019.08.022 (2020).

11 Jankowicz-Szymańska, A., Wódka, K., Kołpa, M. \& Mikołajczyk, E. Foot longitudinal arches in obese, overweight and normal weight females who differ in age. Homo69, 37-42 https://doi.org/10.1016/j.jchb.2018.03.001 (2018).

12 Xu, M., Hong, Y., Li, J. X. \& Wang, L. Foot Morphology in Chinese School Children Varies by Sex and Age. Med Sci Monit24, 4536-4546 https://doi.org/10.12659/msm.906030 (2018).

13 Tong, J. W. \& Kong, P. W. Medial Longitudinal Arch Development of Children Aged 7 to 9 Years: Longitudinal Investigation. Phys Ther96, 1216-1224 https://doi.org/10.2522/ptj.20150192 (2016).

14 Stovitz, S. D., Pardee, P. E., Vazquez, G., Duval, S. \& Schwimmer, J. B. Musculoskeletal pain in obese children and adolescents. Acta Paediatr97, 489-493 https://doi.org/10.1111/j.1651-2227.2008.00724.x (2008).

15 Gravante, G., Russo, G., Pomara, F. \& Ridola, C. Comparison of ground reaction forces between obese and control young adults during quiet standing on a baropodometric platform. Clin Biomech (Bristol, Avon)18, 780-782 https://doi.org/10.1016/s0268-0033(03)00123-2 (2003).

16 Evans, A. M., Copper, A. W., Scharfbillig, R. W., Scutter, S. D. \& Williams, M. T. Reliability of the foot posture index and traditional measures of foot position. J Am Podiatr Med Assoc93, 203-213 https://doi.org/10.7547/87507315-93-3-203 (2003).

17 Menz, H. B. \& Munteanu, S. E. Validity of 3 clinical techniques for the measurement of static foot posture in older people. J Orthop Sports Phys Ther35, 479-486 https://doi.org/10.2519/jospt.2005.35.8.479 (2005).

18 Vinicombe, A., Raspovic, A. \& Menz, H. B. Reliability of navicular displacement measurement as a clinical indicator of foot posture. J Am Podiatr Med Assoc91, 262-268 https://doi.org/10.7547/87507315-91-5-262 (2001).

19 Williams, D. S. \& McClay, I. S. Measurements used to characterize the foot and the medial longitudinal arch: reliability and validity. Phys Ther80, 864871 (2000).

20 Delgado-Abellán, L., Aguado, X., Jiménez-Ormeño, E., Mecerreyes, L. \& Alegre, L. M. Foot morphology in Spanish school children according to sex and age. Ergonomics57, 787-797 https://doi.org/10.1080/00140139.2014.895055 (2014).

21 De Mits, S. et al. Reliability and validity of the Infoot 3D foot digitizer for normal healthy adults. Footwear Science2, 65-75 (2010).

22 Hillstrom, H. J. et al. Foot type biomechanics part 1: structure and function of the asymptomatic foot. Gait Posture37, 445-451 https://doi.org/10.1016/j.gaitpost.2012.09.007 (2013).

23 Aboelnasr, E. A., El-Talawy, H. A., Abdelazim, F. H. \& Hegazy, F. A. Sensitivity and specificity of normalized truncated navicular height in assessment of static foot posture in children aged 6-12 years. Hong Kong Physiotherapy Journa/39, 15-23 (2019).

24 Dowling, A. M., Steele, J. R. \& Baur, L. A. Does obesity influence foot structure and plantar pressure patterns in prepubescent children? Int J Obes Relat Metab Disord25, 845-852 https://doi.org/10.1038/sj.ijo.0801598 (2001).

Page 5/10 
25 Riddiford-Harland, D. L., Steele, J. R. \& Storlien, L. H. Does obesity influence foot structure in prepubescent children? Int J Obes Relat Metab Disord24,

541-544 https://doi.org/10.1038/sj.ijo.0801192 (2000).

26 Butterworth, P. A. et al. Foot posture, range of motion and plantar pressure characteristics in obese and non-obese individuals. Gait Posture41, 465-469 https://doi.org/10.1016/j.gaitpost.2014.11.010 (2015).

27 Cole, T. J., Bellizzi, M. C., Flegal, K. M. \& Dietz, W. H. Establishing a standard definition for child overweight and obesity worldwide: international survey. Bmj320, 1240-1243 https://doi.org/10.1136/bmj.320.7244.1240 (2000).

28 Hill, M., Naemi, R., Branthwaite, H. \& Chockalingam, N. The relationship between arch height and foot length: Implications for size grading. App/ Ergon59, 243-250 https://doi.org/10.1016/j.apergo.2016.08.012 (2017).

29 Mickle, K. J., Steele, J. R. \& Munro, B. J. Is the foot structure of preschool children moderated by gender? J Pediatr Orthop28, 593-596 https://doi.org/10.1097/BPO.0b013e318173f782 (2008).

30 Drefus, L. C., Kedem, P., Mangan, S. M., Scher, D. M. \& Hillstrom, H. J. Reliability of the arch height index as a measure of foot structure in children. Pediatric Physical Therapy29, 83-88 (2017).

\section{Declarations}

Acknowledgements: none

\section{Author contribution:}

- Conceived and designed the experiments: DY Jung. Performed the experiments: DY Jung, EK Koh, KN Park. Analyzed the data: DY Jung, KN Park. Contributed with materials and analysis tools: EK Koh. Wrote the paper: DY Jung, EK Koh, KN Park. Approved the final version to be submitted: DY Jung, EK Koh, KN Park

\section{Funding:}

- This paper was supported by Joongbu University Research \& Development Fund, in 2020.

\section{Competing interests:}

- The authors declare no competing interests.

\section{Ethics approval: Yes}

- This research has been approved by the research ethics committee of the Joongbu University.

\section{Tables}

TABLE 1. Spearman's correlation coefficients among variables

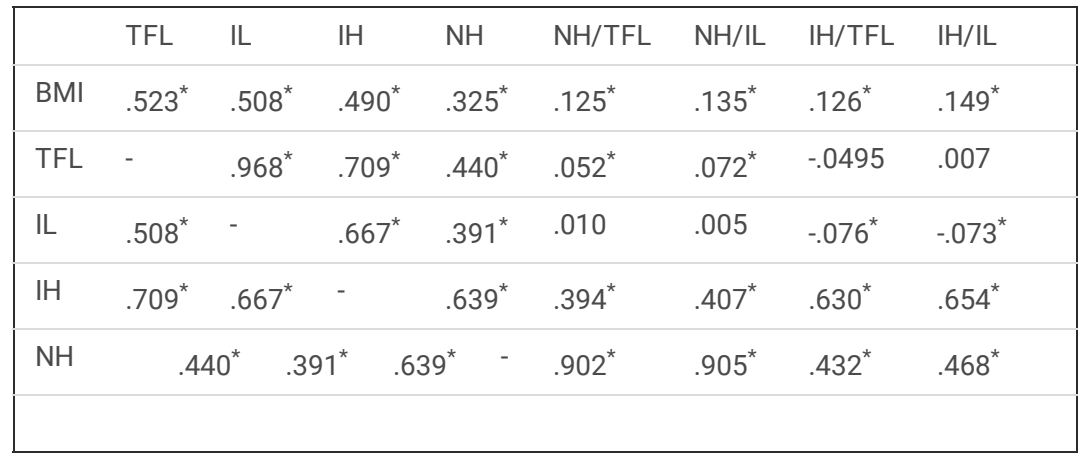

${ }^{*}$ Correlation is significant $(p<$.05). BMl; body mass index; TFL, total foot length; IL, instep length; IH, instep height; $\mathrm{NH}$, navicular height.

TABLE 2. Comparison of all foot measurements according to age and gender 


\begin{tabular}{|c|c|c|c|c|c|c|c|c|c|c|c|c|c|}
\hline \multirow{2}{*}{ Variables } & \multicolumn{3}{|c|}{$8-10$ years } & \multicolumn{3}{|c|}{$11-13$ years } & \multicolumn{3}{|c|}{$14-16$ years } & \multicolumn{3}{|c|}{$17-19$ years } & \multirow{2}{*}{$\begin{array}{l}\text { Total } \\
\text { Male } \\
(n=18\end{array}$} \\
\hline & $\begin{array}{l}\text { Male } \\
(n=142)\end{array}$ & $\begin{array}{l}\text { Female } \\
(n=145)\end{array}$ & $\begin{array}{l}\text { Total } \\
(\mathrm{n}=287)\end{array}$ & $\begin{array}{l}\text { Male } \\
(\mathrm{n}=187)\end{array}$ & $\begin{array}{l}\text { Female } \\
(n=191)\end{array}$ & $\begin{array}{l}\text { Total } \\
(\mathrm{n}=378)\end{array}$ & $\begin{array}{l}\text { Male } \\
(n=202)\end{array}$ & $\begin{array}{l}\text { Female } \\
(n=204)\end{array}$ & $\begin{array}{l}\text { Total } \\
(\mathrm{n}=406)\end{array}$ & $\begin{array}{l}\text { Male } \\
(n=186)\end{array}$ & $\begin{array}{l}\text { Female } \\
(n=194)\end{array}$ & $\begin{array}{l}\text { Total } \\
(\mathrm{n}=380)\end{array}$ & \\
\hline $\begin{array}{l}\text { TFL } \\
(\mathrm{mm})\end{array}$ & $\begin{array}{l}210.77 \\
(14.3)^{\mathrm{a} \rrbracket}\end{array}$ & $\begin{array}{l}205.68 \\
(12.91)\end{array}$ & $\begin{array}{l}208.20 \\
(13.85)^{a^{\star}}\end{array}$ & $\begin{array}{l}235.70 \\
(15.26)^{\natural}\end{array}$ & $\begin{array}{l}228.22 \\
(10.29)\end{array}$ & $\begin{array}{l}231.92 \\
(13.5)^{\star}\end{array}$ & 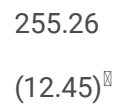 & $\begin{array}{l}234.19 \\
(9.63)\end{array}$ & $\begin{array}{l}244.67 \\
(15.32)^{\star}\end{array}$ & $\begin{array}{l}257.83 \\
(11.35)^{\mathbb{Z}}\end{array}$ & $\begin{array}{l}234.05 \\
(9.61)\end{array}$ & $\begin{array}{l}245.69 \\
(15.86)\end{array}$ & $\begin{array}{l}242.0^{\circ} \\
(22.28\end{array}$ \\
\hline IL (mm) & $\begin{array}{l}157.13 \\
(11.09)\end{array}$ & $\begin{array}{l}152.58 \\
(9.87)\end{array}$ & $\begin{array}{l}154.83 \\
(10.72)^{\star}\end{array}$ & $\begin{array}{l}175.08 \\
(11.38)^{\rrbracket}\end{array}$ & $\begin{array}{l}167.61 \\
(8.49)\end{array}$ & $\begin{array}{l}171.30 \\
(10.69)^{\star}\end{array}$ & $\begin{array}{l}187.04 \\
(9.919)^{\mathbb{Z}}\end{array}$ & $\begin{array}{l}172.40 \\
(7.45)\end{array}$ & $\begin{array}{l}179.68 \\
(11.41)^{\star}\end{array}$ & $\begin{array}{l}188.89 \\
(8.53)^{\bigotimes}\end{array}$ & $\begin{array}{l}171.68 \\
(7.62)\end{array}$ & $\begin{array}{l}180.10 \\
(11.80)\end{array}$ & $\begin{array}{l}178.48 \\
(15.70\end{array}$ \\
\hline $\mathrm{IH}(\mathrm{mm})$ & $\begin{array}{l}48.41 \\
(4.41)^{\mathbb{Z}}\end{array}$ & $\begin{array}{l}46.97 \\
(4.55)\end{array}$ & $\begin{array}{l}47.68 \\
(4.53)^{*}\end{array}$ & $\begin{array}{l}55.00 \\
(5.23)^{\bigotimes}\end{array}$ & $\begin{array}{l}51.93 \\
(4.76)\end{array}$ & $\begin{array}{l}53.45 \\
(5.25)^{\star}\end{array}$ & $\begin{array}{l}59.68 \\
(4.71)^{\bigotimes}\end{array}$ & $\begin{array}{l}54.91 \\
(4.33)\end{array}$ & $\begin{array}{l}57.28 \\
(5.10)^{\star}\end{array}$ & $\begin{array}{l}60.04 \\
(4.60)^{\bigotimes}\end{array}$ & $\begin{array}{l}54.43 \\
(4.25)\end{array}$ & $\begin{array}{l}57.17 \\
(5.24)\end{array}$ & $\begin{array}{l}56.32 \\
(6.51)\end{array}$ \\
\hline $\mathrm{NH}(\mathrm{mm})$ & $\begin{array}{l}32.14 \\
(7.18)^{\rrbracket}\end{array}$ & $\begin{array}{l}29.66 \\
(5.94)\end{array}$ & $\begin{array}{l}30.89 \\
(6.69)^{\star}\end{array}$ & $\begin{array}{l}36.20 \\
(6.97)^{\llbracket}\end{array}$ & $\begin{array}{l}34.71 \\
(6.22)\end{array}$ & $\begin{array}{l}35.44 \\
(6.64)^{\star}\end{array}$ & $\begin{array}{l}40.79 \\
(7.38)^{\rrbracket}\end{array}$ & $\begin{array}{l}37.54 \\
(6.56)\end{array}$ & $\begin{array}{l}39.16 \\
(7.16)^{\star}\end{array}$ & $\begin{array}{l}41.63 \\
(8.31)^{\bigotimes}\end{array}$ & $\begin{array}{l}38.57 \\
(6.69)\end{array}$ & $\begin{array}{l}40.07 \\
(7.67)\end{array}$ & $\begin{array}{l}38.10 \\
(8.32)\end{array}$ \\
\hline $\mathrm{NH} / \mathrm{TFL}$ & $\begin{array}{l}.152 \\
(.032)\end{array}$ & $\begin{array}{l}.144 \\
(.028)\end{array}$ & $\begin{array}{l}.148 \\
(.03)^{\star}\end{array}$ & $\begin{array}{l}.154 \\
(.028)\end{array}$ & $\begin{array}{l}.152 \\
(.028)\end{array}$ & $\begin{array}{l}.153 \\
(.028)^{*}\end{array}$ & $\begin{array}{l}.160 \\
(.029)\end{array}$ & $\begin{array}{l}.161 \\
(.029)\end{array}$ & $\begin{array}{l}.160 \\
(.029)^{*}\end{array}$ & $\begin{array}{l}.162 \\
(.033)\end{array}$ & $\begin{array}{l}.165 \\
(.029)\end{array}$ & $\begin{array}{l}.163 \\
(.031)\end{array}$ & $\begin{array}{l}.157 \\
(.031)\end{array}$ \\
\hline $\mathrm{NH} / \mathrm{IL}$ & $\begin{array}{l}.205 \\
(.043)\end{array}$ & $\begin{array}{l}.195 \\
(.039)\end{array}$ & $\begin{array}{l}.200 \\
(.041)^{\star}\end{array}$ & $\begin{array}{l}.207 \\
(.039)\end{array}$ & $\begin{array}{l}.208 \\
(.039)\end{array}$ & $\begin{array}{l}.207 \\
(.039)^{\star}\end{array}$ & $\begin{array}{l}.219 \\
(.041)\end{array}$ & $\begin{array}{l}.218 \\
(.040)\end{array}$ & $\begin{array}{l}0.218 \\
(.041)^{*}\end{array}$ & $\begin{array}{l}.221 \\
(.046)\end{array}$ & $\begin{array}{l}.225 \\
(.040)\end{array}$ & $\begin{array}{l}.223 \\
(.043)\end{array}$ & $\begin{array}{l}.213 \\
(.043)\end{array}$ \\
\hline IH/TFL & $\begin{array}{l}.230 \\
(.018)\end{array}$ & $\begin{array}{l}.229 \\
(.019)\end{array}$ & $\begin{array}{l}.229 \\
(.018)\end{array}$ & $\begin{array}{l}.233 \\
(.018)^{\bigotimes}\end{array}$ & $\begin{array}{l}.228 \\
(.020)\end{array}$ & $\begin{array}{l}.231 \\
(.019)^{\star}\end{array}$ & $\begin{array}{l}.234 \\
(.018)\end{array}$ & $\begin{array}{l}.235 \\
(.019)\end{array}$ & $\begin{array}{l}.234 \\
(.018)\end{array}$ & $\begin{array}{l}.233 \\
(.018)\end{array}$ & $\begin{array}{l}.233 \\
(.018)\end{array}$ & $\begin{array}{l}.233 \\
(.018)\end{array}$ & $\begin{array}{l}.233 \\
(.018)\end{array}$ \\
\hline $\mathrm{IH} / \mathrm{IL}$ & $\begin{array}{l}.309 \\
(.025)\end{array}$ & $\begin{array}{l}.308 \\
(.028)\end{array}$ & $\begin{array}{l}.308 \\
(.026)\end{array}$ & $\begin{array}{l}.314 \\
(.025)\end{array}$ & $\begin{array}{l}.310 \\
(.031)\end{array}$ & $\begin{array}{l}.312 \\
(.028)^{*}\end{array}$ & $\begin{array}{l}.320 \\
(.026)\end{array}$ & $\begin{array}{l}.319 \\
(.027)\end{array}$ & $\begin{array}{l}.319 \\
(.027)\end{array}$ & $\begin{array}{l}.318 \\
(.025)\end{array}$ & $\begin{array}{l}.317 \\
(.026)\end{array}$ & $\begin{array}{l}.318 \\
(.025)\end{array}$ & $\begin{array}{l}.316 \\
(.026)\end{array}$ \\
\hline
\end{tabular}

a mean (standard deviation); TFL, total foot length; IL, instep length; IH, instep height; NH, navicular height.

${ }^{\text {* }}$ show significant differences between consecutive years; ${ }^{\circledR}$ show significant differences between gender in each age group.

TABLE 3.

Distribution of foot types based on classification of NAH by age groups (number, \%)

\begin{tabular}{|lllll|}
\hline & $\mathrm{IH} / \mathrm{IL}$ & \multicolumn{3}{l|}{$\mathrm{NH} / \mathrm{IL}$} \\
\cline { 2 - 5 } & Pes planus & Rectus & Pes planus & Rectus \\
\hline 8-10 years & $267(93.0)$ & $20(7.0)$ & $120(41.8)$ & $167(58.2)$ \\
\hline $11-13$ years & $340(89.9)$ & $38(10.1)$ & $137(36.2)$ & $241(63.8)$ \\
\hline $14-16$ years & $336(82.8)$ & $70(17.2)$ & $122(30.0)$ & $284(70.0)$ \\
\hline $17-19$ years & $327(85.8)$ & $54(14.1)$ & $95(25.0)$ & $286(75.0)$ \\
\hline Total & $1269(87.5)$ & $182(12.6)$ & $474(32.7)$ & $977(67.3)$ \\
\hline
\end{tabular}

$\mathrm{NAH}$, normalized arch height; IH, instep height; IL, instep length; $\mathrm{NH}$, navicular height.

\section{Figures}




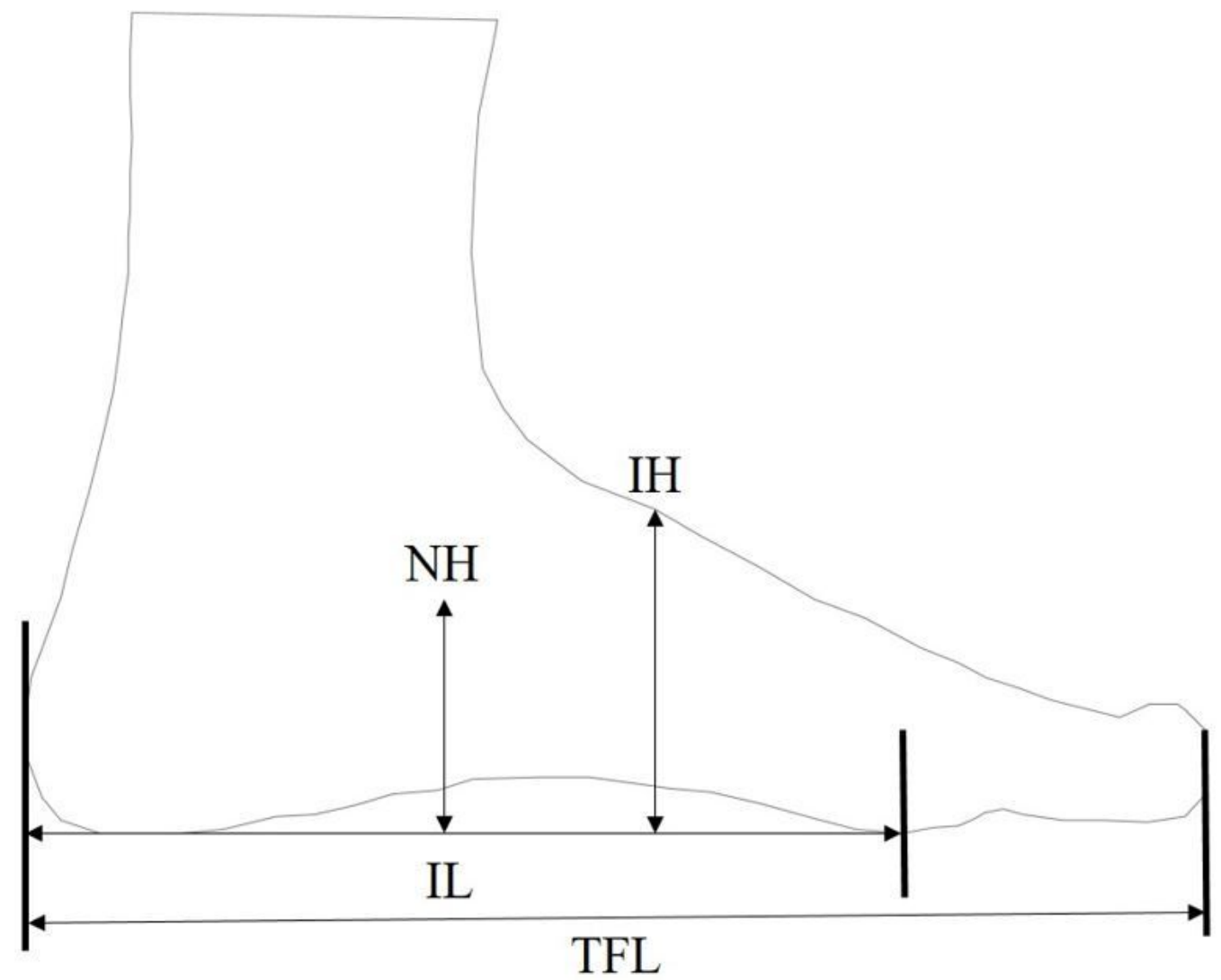

Figure 1

Measurements of foot length and arch height using 3D foot scanning (TFL: total foot length. IL: instep length, NH: navicular height, IH: instep height) 

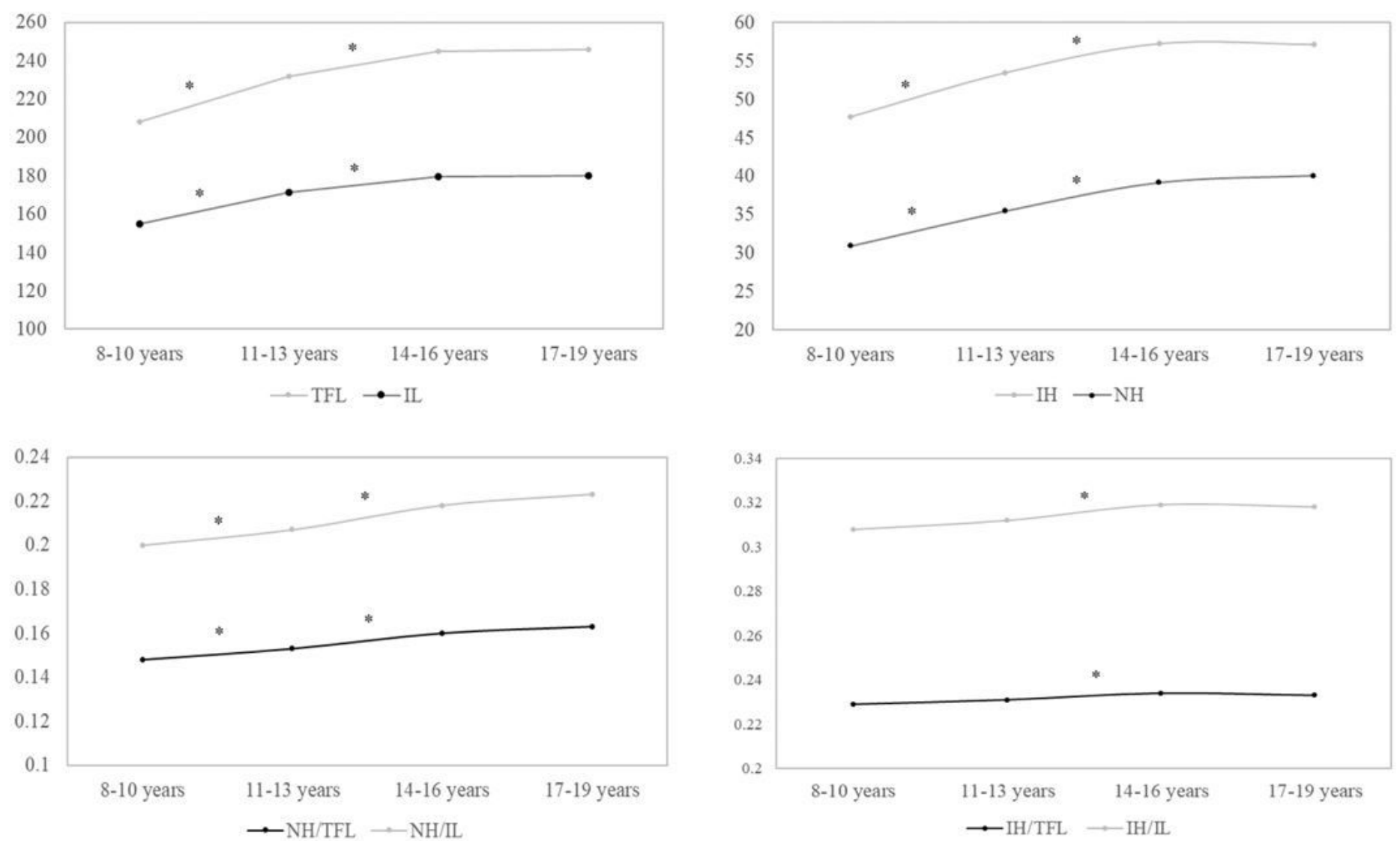

\section{Figure 2}

Trends of growth of foot length and arch height over age. * show significant differences between consecutive years.; TFL, total foot length; IL, instep length; IH, instep height; $\mathrm{NH}$, navicular height.

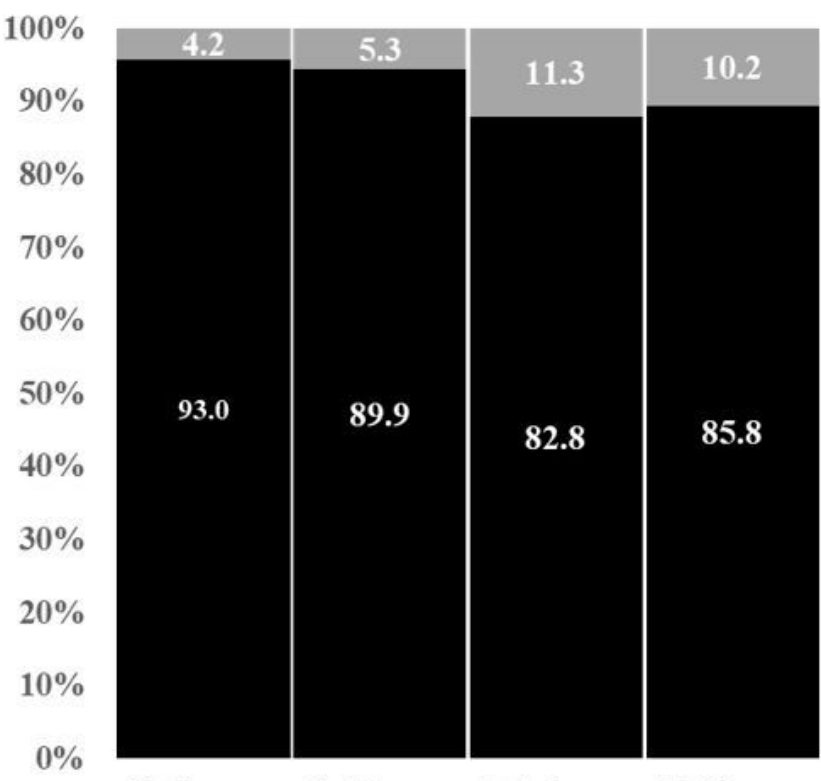

8-10 years $11-13$ years $14-16$ years $17-19$ years

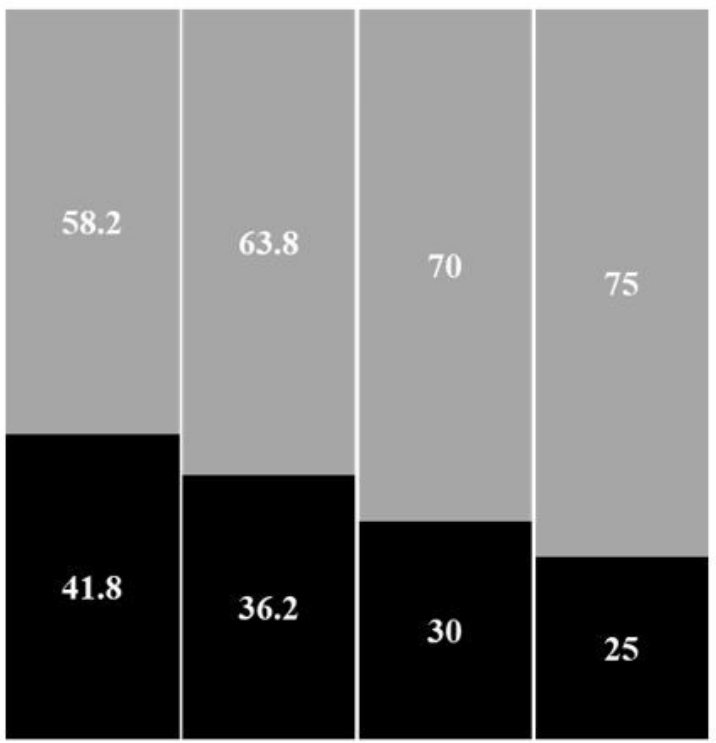

8-10 years $11-13$ years $14-16$ years $17-19$ years

(B)

(A)

- Pes planus $=$ Rectus 
Figure 3

Distribution of foot types by age groups, classified based on the criteria of NH/IL (A) and IH/IL (B). NH, navicular height; IL, instep length; IH, instep height. 